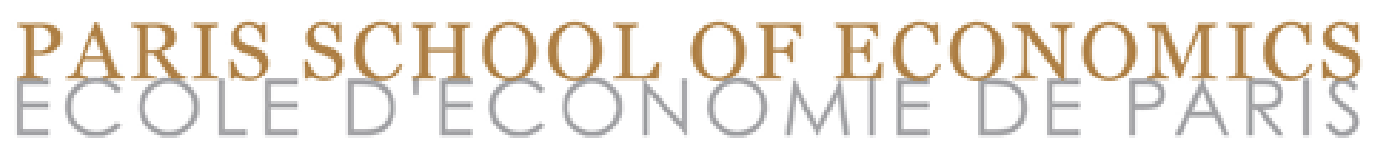

WORKING PAPER N² 2012 - 19

A Model of Transfer Problem with Application to LDCs

Mouhamadou Sy

Hamidreza Tabarraei

JEL Codes: F31, F35, F41

Keywords: Dutch Disease ; Transfer Problem ; Capital Inflows ; Real Exchange Rate

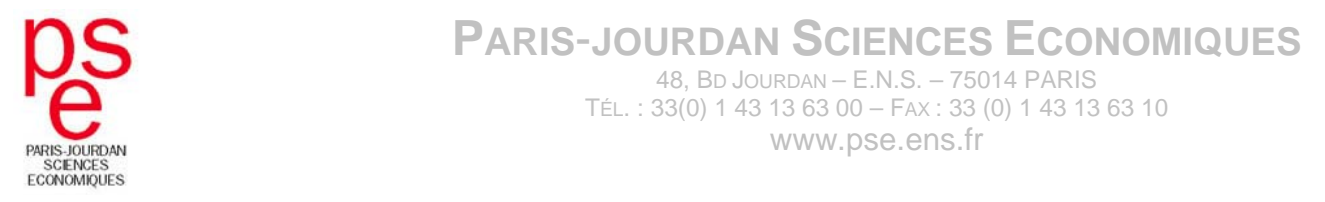

CENTRE NATIONAL DE LA RECHERCHE SCIENTIFIQUE - ECOLE DES HAUTES ETUdES EN SCIENCES SOCIALES 


\title{
A Model of Transfer Problem with Application to LDCs *
}

\author{
Mouhamadou $\mathrm{Sy}^{\dagger}$ \\ Hamidreza Tabarraei ${ }^{\ddagger}$
}

April 2012, forthcoming, Annals of Economics and Statistics

This paper studies a form of Dutch disease known as the Transfer problem in developing countries. On the theoretical side, we propose a model which unifies the channel proposed by Keynes [1929], Balassa [1964] and Samuelson [1964], and Yano and Nugent [1999]. The real exchange rate dynamic is decomposed in three components: the productivity differential, the terms-of-trade, and international transfer. The effects of international transfer on the real exchange rate depend mainly on the propensity of governments to subsidize the tradable or the non-tradable sectors. In the empirical section we take into account the heterogeneity of the sample, the dynamic of the real exchange rate and the non stationary nature of the data. Furthermore, we demonstrate empirically that the channels identified by Balassa, Samuelson and Keynes are the main driving forces of real exchange rate movements in developing countries. The Balassa-Samuelson effect by itself accounts for $57 \%$ of RER variations while capital inflows account only for $19 \%$ of RER variations. The Transfer problem through capital inflows is not rejected but its impact on RER movements in the LDCs is weak

JEL Classification: F31, F35, F41 Key words: Dutch Disease, Transfer Problem, Capital Inflows, Real Exchange Rate.

\footnotetext{
*An earlier version of this paper was circulated under the title "Capital inflows and exchange rate in LDCs: The Dutch disease problem revisited". We thank the editor Francois Langot and two anonymous referees for very helpful remarks and suggestions. We are grateful to Daniel Cohen, Robert Kollmann, Jean-Paul Nicolai, Asne Oyehaug, Hashem Pesaran, Richard Portes, Romain Rancière, Ron P. Smith and Gregor Schwerhoff for helpful comments. We are also grateful to comments from seminar participants at Paris School of Economics and comments from participants to the Conference on Natural Resources and Economic Development: Risks and Policy Challenges, Dubai and to the 17th International Panel Data Conference, Montreal. Any errors remain our own. A technical appendix accompanies this paper, it is available upon request. Mouhamadou Sy gratefully acknowledges financial support from the Region Ile-de-France and the Cepremap.

${ }^{\dagger}$ Corresponding Author: Mouhamadou Sy - Centre d'Analyse Stratégique, 18 rue de Martignac, 75700 Paris SP 07. Emails: mouhamadou.sy@strategie.gouv.fror sy@pse.ens.fr.

${ }^{\ddagger}$ Hamidreza Tabarraei - Paris School of Economics, 48 Boulevard Jourdan, 75014 Paris. Email: tabarraei@pse.ens.fr
} 


\section{Introduction}

'The interesting question is not the sign of the Dutch Disease effect of aid, but only the size of the effect." Doucouliagos and Paldam [2009]

There is abundant literature on the impact of capital inflows on economic development. However, we observe that while there exists large capital inflows toward developing countries, the impact on their growth rate is ambiguous. Capital inflows include foreign aid, foreign direct investment, and remittances. For example, to achieve the millennium development goals, developed countries should spend more than $50 \$$ billions before 2015 in foreign aid. Most of the studies that have assessed the impact of foreign aid on the economic growth present different outcomes. Recently, some studies with convincing methodologies conclude that foreign aid has a weak impact on growth. Burnside and Dollar [2000] concluded that aid is only efficient under certain conditions, while Rajan and Subramanian [2008] showed that foreign aid has no impact on growth.

Graph 1 shows the evolution of the three international capital inflows in LDCs, namely foreign direct investment, foreign aid, and remittances. The general picture is that every component have exhibited a rapid evolution since the early eighties. So it is important to determine what the effect of these capital inflows should be on their economic growth. But, as we highlighted earlier, the literature presents different outcomes. This paper attempts to shed new light on the impact of capital inflows on economic growth by focusing on the channel between capital inflows and economic growth, that is, the real exchange rate. This channel, which is a form of the Dutch disease, is known as the transfer problem.

The negative consequences of capital flows on economic development are called the Dutch disease problem. The Dutch disease theory states that capital inflows have a negative impact on economic growth through real exchange rate over-valuation. The term Dutch disease was used for the first time by The Economist magazine in 1977, to describe the economic problems in the Netherlands after they discovered natural resources in the North sea. Generally speaking, economists used this term to describe the slowdown of exports caused by real exchange rate over-valuation due to exploitation of natural resources such as gas or oil (Barder [2006]). Now, this term is used to explain developing countries economic problems following a discovery of natural resources or huge capital inflows like foreign aid, foreign direct investment or problems linked to huge sovereign debt. Now in the literature both Dutch disease and transfer problem hint at the same concept. In both theories, the real exchange rate plays a key role. The Dutch disease is a theory that considers the real exchange rate as a channel between capital inflows and economic growth. In this paper, however, we focus only on the link between capital inflows and the real exchange rate.

As mentioned earlier, this paper is not the first of its kind that attempts to study this question. However, the outcomes of previous studies tend to not agree with each other. In our view, these differences are mainly explained by the following reasons: (1) the estimation methods in some studies are weak, (2) inadequate estimation methods for the subject, (3) the papers focus on the sign of the capital inflows impact. However, as Doucouliagos and Paldam [2009] mention, the size of the effect matters more than the sign of the effect. (4) The previous literature (the exception can be Lane and Milesi-Ferretti [2004]) is based on a direct estimation of reduced form equation without a micro-foundation. Testing the effect of capital inflows directly without any theoretical constrains provides a higher degree of freedom in terms of specifying the equation, controlling variables and interpreting the results.

In order to overcome these problems, we try to shed new light on the literature both on the theoretical and 
on the empirical sides. On the theoretical side, so far, the economic literature has identified three main channels to explain the long-run behavior of the real exchange rate. The first framework was developed by Keynes [1929] in order to explain the impact of German's transfers as first world war compensations, on the real exchange rate of the winners countries. In his framework, the terms-of-trade was the channel. The second channel was developed by Balassa [1964] and Samuelson [1964] separately to explain why real exchange rates in growing developing countries tended to appreciate. In this theory, the productivity differential was the channel. The last one was developed rather recently by Yano and Nugent [1999] to explain how capital inflows and mainly foreign aid can affect the real exchange rate. In this theory, the impact of capital inflows on the allocation between the tradable and non-tradable goods was the channel. The transfer problem as a form of the Dutch disease has two channels: The one described by Keynes [1929] and the other described by Yano and Nugent [1999]. We will elaborate on each channel in section II.

Theoretically, we do not propose a new channel. Our contribution is thus to put together these three channels in one testable equation. This helps us to better interpret the empirical results and to better identify the economic mechanisms that drive the real exchange rate.

In our model, the real exchange rate depends on the productivity differentials between the tradable and the non-tradable sectors. This is consistent with the studies by Balassa [1964] and Samuelson [1964]. For the second channel, which consists of the terms-of-trade influence on the real exchange rate, we show that the likelihood of the transfer problem described by Keynes depends on the elasticity of substitution between the tradable and non-tradable goods. Moreover, we demonstrate that the real exchange rate depends on international capital flows through the propensity of government to spend the received capital inflows on traded or non-traded goods. In other words, the effects of foreign aid, foreign direct investment, and remittances ultimately depend on the sector that they are spent on. This is consistent with the study by Yano and Nugent [1999].

Empirically, we estimate the key equation in the paper by using recent advances in time series and panel econometrics techniques. We also emphazize each channel. We show that the part of real exchange rate variation explained by capital inflows is only 19\%. The mechanism described by Balassa and Samuelson is by far the most important channel because it explains $57 \%$ of the real exchange rate variation. Finally the channel described by Keynes explains $24 \%$. If we distinguish the various components of capital inflows, we find that foreign aid, foreign direct investment, and remittances explain respectively $9 \%$, $9 \%$, and $1 \%$ of the real exchange rate variation.

The remainder of the paper is organized as follow: In the next section, a simple model is presented in order to explain the transfer paradox. Section 3 contains the empirical analysis. Finally the last section concludes the paper.

\section{Theoretical Framework}

\section{II.1 Overview of the Model: Keynes [1929], Balassa [1964] and Samuelson [1964], Yano and Nugent [1999] in One Testable Equation}

The transfer problem theory was first developed as part of the discussions between J. M. Keynes and B. Ohlin about the consequences of German compensations at the end of world war I. To pay the transfers, Germany would have needed to export more and import less, i.e. they need to have lower export prices 
with respect to import prices. The improvment of the terms-of-trade of the winner countries could have produced an appreciation of their real exchange rates through the Dutch disease "spending effect", see section II.5. Later, in the early fifties, Samuelson [1952] formalized the question and confirmed that under some conditions (when there are transportation costs or other trade frictions) the transfer paradox problem exists, i.e. an appreciation of the real exchange rate following a deterioration of the terms-oftrade. According to Keynes, the primary channel between the real exchange rate and the transfers is the terms-of-trade. Let us call this the relative price channel.

Another channel, highlighted in Yano and Nugent [1999], plays an important role too. In this mechanism, capital inflows affect the allocation between tradable and non-tradable goods for the receiving economy. How can these capital inflows cause a real exchange rate appreciation? By raising the amount of available non-tradable goods in the economy at the expense of tradable goods. When a government receives foreign currencies due to the capital inflows, it converts them into the domestic money at its central bank. In these countries, capital inflows are mainly spent on education, health, etc. In other words, the social sector benefits from most of the capital inflows. By building roads, hospitals or other social infrastructure, an excess demand for non-tradable goods is generated. If the supply side is not flexible enough to cope with this new demand due to, for example, supply constraints, limited capacity of factor utilization or a lack of skilled manpower (a non-restrictive assumptions in developing countries) then the production cost in the non-tradable sector increases. Consequently, the production cost of the tradable sector also increases because it is measured in the local currency. However their prices remain constant because they are fixed by international markets. Thus, capital inflows lead to a rise in demand for non-tradable goods at the expense of tradable goods, which is followed by an increase in the price of non-tradable goods relative to the price of tradable goods. Consequently the real exchange rate appreciates since the real exchange rate is simply the relative price between non-tradable and tradable goods. Let us call this channel the relative quantity channel.

By proposing a simple model, these two different channels in the transfer problem can be taken into account. The framework is built on Asea and Mendoza [1994], and Wickens [2008]. We consider a small open economy with a representative infinitely-lived agent. Production factors of all goods are owned by this representative agent. The economy produces two goods: tradable and non-tradable. The agent also consumes another tradable - import - good.

The real exchange rate can be decomposed into three components: the first component is the relative price channel described above. We will detail the conditions under which the mechanism highlighted by Keynes [1929] can produce a transfer paradox. The second component is the relative quantity channel. Here also, we will show what conditions under which the mechanism described by Yano and Nugent [1999] can generate a transfer problem. The third component is the traditional Balassa-Samuelson's mechanism: the relative productivity channel.

This decomposition of the real exchange between these three components will form the basis of our empirical analysis. The reader can refer directly to the equation (10) in order to skip the model if necessary. More details on the model can be found in the web technical appendix of this paper. 


\section{II.2 Households}

The representative consumer maximizes the expected presented discount value of utilities from the three consumption goods: tradable, non-tradable and import.

$$
\max U\left(C_{t}\right)=\sum_{s=0}^{\infty} \tilde{\beta}^{s}\left[\ln \left(C_{t+s}\right)\right]
$$

with

$$
C_{t}=\frac{\left[\left(C_{t}^{M}\right)^{\rho}\left(C_{t}^{T}\right)^{1-\rho}\right]^{1-\gamma}\left(C_{t}^{N}\right)^{\gamma}}{\gamma^{\gamma}(1-\gamma)^{1-\gamma}}
$$

where $C_{t}^{M}$ is the consumption of imported goods, $C_{t}^{T}$ the consumption of home tradable goods and $C_{t}^{N}$ the consumption of non-tradable goods. $\rho$ is the elasticity of substitution between import and home tradable goods and $\gamma$ is the elasticity of substitution between all tradable - home and foreign - and non-tradable goods. The economy's constraint can be written as:

$$
P^{T} F\left(K^{T}, L^{T}\right)+P^{N} G\left(K^{N}, L^{N}\right)=P^{T} C^{T}+P^{N} C^{N}+P^{M} C^{M}+P^{T} I^{T}+P^{N} I^{N}
$$

$P_{t}^{T}, P_{t}^{N}$, and $P_{t}^{M}$ represent respectively the prices of the tradable good, non-tradable good, and imported good. $F($.$) and G($.$) are the production function in the tradable and the non-tradable sectors respectively.$ We will give an explicit formulation for $F($.$) and G($.$) in section II.4. I^{T}$ and $I^{N}$ are the investments in the tradable and the non-tradable sectors respectively. $K_{t}^{T}$ and $K_{t}^{N}$ represent the physical capital in the tradable sector and non-tradable sector respectively. Labor is assumed to be mobile across sectors. Households supply labor inelastically such that $L=L^{T}+L^{N}$ where $L^{T}$ is labor in the traded sector and $L^{N}$ is labor in the non-traded sector. The physical capital is also mobile ${ }^{1}$ across sectors such that $K=K^{T}+K^{N}$. We suppose that the tradable and the non-tradable sectors have the same capital intensity. Physical capital earn a rental price $r^{T}$ and $r^{N}$ respectively, depreciates at the same rate $\delta$, and can be augmented by sector's specific investments: $I_{t}^{T}$ and $I_{t}^{N}$. The the law of motion of capital accumulation in each sector is then:

$$
\begin{aligned}
& \Delta K_{t+1}^{T}=I_{t}^{T}-\delta K_{t}^{T} \\
& \Delta K_{t+1}^{N}=I_{t}^{N}-\delta K_{t}^{N}
\end{aligned}
$$

The firms' maximization problem given the rental price for capital, $r_{t}^{i}$ and the wage rate for labour, $w_{t}^{i} \quad i=T, N$ induces the zero profit conditions

$$
\begin{aligned}
F\left(K_{t}^{T}, L_{t}^{T}\right) & =r^{T} K_{t}^{T}+w_{t}^{T} L_{t}^{T} \\
G\left(K_{t}^{N}, L_{t}^{N}\right) & =r^{N} K_{t}^{N}+w_{t}^{N} L_{t}^{N}
\end{aligned}
$$

\footnotetext{
${ }^{1}$ The presence of physical capital is not needed to obtain the main equation (10) of the paper. No component of the equilibrium real exchange rate - the terms-of-trade, the Balassa-Samuelson effect, and the Transfer effect - depends on capital. We introduce capital for a pure mathematical purpose. It allows us to have a more compact version of equation (10) by using some properties of the Cobb-Douglass production function.
} 
Since production factors are mobile in each sector and no adjustment costs are imposed on capital and labour, the zero-profit condition leads us to an equality between the rate of remuneration of each factor and its marginal production.

The economy's constraint can be rewritten as:

$$
\begin{aligned}
P^{T} r^{T} K_{t+s}^{T}+P^{T} w^{T} L_{t+s}^{T}+r^{N} & P_{t+s}^{N} K_{t+s}^{N}+w^{N} P_{t+s}^{N}\left(L-L_{t+s}^{T}\right) \\
= & P^{T} C_{t+s}^{T}+P_{t+s}^{N} C_{t+s}^{N}+P_{t+s}^{M} C_{t+s}^{M} \\
& +(1-\delta)\left[P^{T} K_{t+s}^{T}+P_{t+s}^{N} K_{t+s}^{N}\right] \\
& +\left[P^{T} K_{t+s+1}^{T}+P_{t+s}^{N} K_{t+s+1}^{N}\right]
\end{aligned}
$$

The representative agent seeks to maximize $\sum_{s=0}^{\infty} \tilde{\beta}^{s}\left[\ln \left(C_{t+s}\right)\right]$ with respect to:

$$
\left\{c_{t+s}^{T}, c_{t+s}^{N}, c_{t+s}^{M}, k_{t+s+1}^{T}, k_{t+s+1}^{N}, L_{t+s}^{T}, L_{t+s}^{N} ; s \geq 0\right\}
$$

The consumer price index consistent with equations (1) and (2) is:

$$
P_{t}=B \times\left[\left(P_{t}^{M}\right)^{\rho}\left(P_{t}^{T}\right)^{1-\rho}\right]^{1-\gamma}\left(P_{t}^{N}\right)^{\gamma}
$$

in which $B$ is a constant (see the appendix). We use the usual definition of the terms-of-trade (TOT) as the ratio of export prices to import prices and we normalize the price of tradable to 1 . Then we can write the consumer price index as:

$$
P_{t}=B \times\left((T O T)^{-\rho}\right)^{1-\gamma}\left(P^{N}\right)^{\gamma}
$$

We now turn to the price determinants of non-tradable goods in the economy.

\section{II.3 Government}

In this model, government behavior is assumed to be very simple. The government receives transfer $(T R)$ from abroad that are denominated in units of tradable. Since the government uses these for domestic production subsidies, international transfers finance both the production of tradable and non-tradable sectors. The government cannot issue bonds ${ }^{1}$, it only relies on transfers for its financing. Therefore, the government budget balance is:

$$
G^{T}+p^{N} G^{N}=T R
$$

\footnotetext{
${ }^{1}$ It is not difficult to introduce bond financing in this model. The government's budget constraint should be written as $G_{t}^{T}+p_{t}^{N} G_{t}^{N}+\left(1+r^{T}\right) B_{t-1}=B_{t}+T R_{t}$. At the equilibrium, the real exchange rate will also depend on the net foreign asset, see Lane and Milesi-Ferretti (2004) who introduce only bond financing. To keep the model simple, we ignore bond financing.
} 


\section{II.4 Firms}

Firms produce two final goods with the following technology:

$$
Y^{i}=A^{i} G^{i}\left(X L^{i}\right)^{\alpha i}\left(K^{i}\right)^{\beta i}
$$

where $i=T, N$ and where labor $(L)$ and capital $(K)$ are factors of production with $\alpha_{i}+\beta_{i}<1$. $X$ is an index of the Harrod-neutral labour-increasing technological progress. It allows balanced longrun growth to be driven by labor augmenting technological progress. $G^{i}, i=T, N$ are government subventions for the production of traded and non-traded goods. $A^{i}$ is stochastic productivity. The total factor productivity for each sector is:

$$
\theta^{i}=A^{i}(X)^{\alpha^{i}}
$$

Maximizing the households utility with respect to labour in the tradable sector generates the non-tradable price index. This is the first equality in the following equation. Therefore by maximizing the firms' production function (4) with respect to labour in each sector, we get:

$$
P^{N}=\frac{w^{T}}{w^{N}}=\frac{\alpha^{T}}{\alpha^{N}} \frac{g^{T}}{g^{N}} \frac{Z^{T}}{Z^{N}}
$$

where $Z^{i}=A^{\alpha i} \Psi^{\alpha i} K^{\beta i}$ and $i=T, N$ is the standard production function. $\Psi^{i}=X L^{i}, i=T, N$ is the effective labor input and $g^{i}=G^{i} / L^{i}, i=T, N$ where $g^{i}$ is the government spending per worker in each sector. Let $z^{i}=Z^{i} / L^{i}$, and $k^{i}=K^{i} / L^{i}, i=T, N$, the output and the capital per worker in each sector. This allows us to rewrite the prices of non-tradable goods in a more compact way: For a Cobb-Douglass function, equation (6) becomes (because $z=(k / z)^{\alpha / \beta}$ )

$$
P^{N}=\frac{\alpha^{T}}{\alpha^{N}} \frac{g^{T}}{g^{N}} \frac{\left(\frac{k^{T}}{z^{T}}\right)^{\alpha^{T} / \beta^{T}}}{\left(\frac{k^{N}}{z^{N}}\right)^{\alpha^{N} / \beta^{N}}}
$$

On the other hand we have $r^{N}=r^{T}$, because of perfect capital mobility. We also know that the rental price in each sector is equal to the marginal product of capital in each sector. Hence by replacing the marginal product of capital in the last equation, we obtain:

$$
\frac{k^{N}}{z^{N}}=\frac{\beta^{N}}{\beta^{T}} \frac{g^{N}}{g^{T}} \frac{k^{T}}{z^{T}}
$$

but since $\beta^{N}=\beta^{T}$, the relative price of non-tradable goods in equation (7) becomes ${ }^{1}$

$$
P^{N}=\frac{\alpha^{T}}{\alpha^{N}}\left(\frac{g^{T}}{g^{N}}\right)^{\frac{\alpha^{N}+\beta^{N}}{\beta^{N}}}\left(\frac{k^{T}}{z^{T}}\right)^{\frac{\alpha^{T}}{\beta^{T}}-\frac{\alpha^{N}}{\beta^{N}}}
$$

${ }^{1} \beta^{N}=\beta^{T}$ because we suppose that the two sectors have the same capital intensity. This assumption is also for a pure mathematical purpose: to rule out the term $\left(\beta^{T} / \beta^{N}\right)^{\alpha^{T} / \beta^{N}}$ from the equilibrium real exchange rate. 
$\left(k^{T} / z^{T}\right)^{\frac{\alpha^{T}}{\beta^{T}}-\frac{\alpha^{N}}{\beta^{N}}}$, the capital-output ratio, is a constant (see appendix) that depends only on preferences and technology parameters. So we can write the final expression for the non-tradable price index as:

$$
P^{N}=C \times \frac{\alpha^{T}}{\alpha^{N}}\left(\frac{g^{T}}{g^{N}}\right)^{\frac{\alpha^{N}+\beta^{N}}{\beta^{N}}}
$$

where $C$ is a constant.

\section{II.5 The Real Exchange Rate}

If we assume that the price of the non-traded goods in the foreign country is normalized to $1^{1}$, we can write the real exchange rate using (3) and (8) :

$$
R E R=B \times C \times\left((T O T)^{-\rho}\right)^{1-\gamma}\left(\frac{\alpha^{T}}{\alpha^{N}}\left(\frac{g^{T}}{g^{N}}\right)^{\frac{\alpha^{N}+\beta^{N}}{\beta^{N}}}\right)^{\gamma}
$$

The log-linearization of the above equation yields:

$$
r \tilde{e} r=\underbrace{-\rho(1-\gamma) \tilde{t o t}}_{\text {Keynes or TOT effect }}+\underbrace{\gamma\left(\tilde{\alpha}^{T}-\tilde{\alpha}^{N}\right)}_{\text {Balassa-Samuelson effect }}+\underbrace{\gamma \omega^{N}\left(\tilde{g}^{T}-\tilde{g}^{N}\right)}_{\text {Yano-Nugent or Transfer effect }}+\zeta
$$

with $\omega^{N}=\left(\alpha^{N}+\beta^{N}\right) / \beta^{N}$ and $\zeta=\log (B \times C)$.

The equilibrium real exchange rate is determined in this model by three factors: The terms-of-trade, the productivity differential, and international transfer.

1. The relative productivity channel or the Balassa-Samuelson effect: $\alpha^{T}$ and $\alpha^{N}$ represent the relative size of effective labor in the tradable and non-tradable sectors respectively. In order to see how they account for the Balassa-Samuelon effect, we need to rewrite equation (5) for total factor productivity. With some manipulation, it is possible to show that the productivity differential between the two sectors can be written as a function of $\alpha^{T}$ and $\alpha^{N}$ such that ${ }^{2}$ :

$$
\ln \left(\frac{\theta_{t+1}^{T}}{\theta_{t}^{T}}\right)-\ln \left(\frac{\theta_{t+1}^{N}}{\theta_{t}^{N}}\right)=\left(\alpha^{T}-\alpha^{N}\right) \ln \omega+\xi_{t+1}
$$

with

$$
\xi_{t+1}=\ln \left(\frac{A_{t+1}^{T}}{A_{t}^{T}}\right)-\ln \left(\frac{A_{t+1}^{N}}{A_{t}^{N}}\right)
$$

which is a stationary process and $\omega=X_{t+1}^{T} / X_{t}^{T}=X_{t+1}^{N} / X_{t}^{N}$.

Since the technical progress, $X_{t}^{i}, i=T, N$ grows with a constant rate $(\omega)$, all changes in the productivity differentials - the Balassa-Samuelson effect - are explained by changes in $\left(\alpha^{T}-\alpha^{N}\right)$,

\footnotetext{
${ }^{1}$ We do not need this assumption to solve the model. We introduce it only to make the final expression of the real exchange rates more understandable.

${ }^{2}$ See Asea and Mendoza (1994) for a complete appraisal of the Balassa-Samuelson effect in general equilibrium
} 
i.e. the allocation of labour between the two sectors ${ }^{1}$. The result is thus consistent with the Balassa and Samuelson's prediction: the real exchange rate is positively related to productivity in the traded sector and negatively related to productivity in the non-traded sectors.

2. The relative quantity channel or the Yano-Nugent effect: International transfers affect the real exchange rate through their impact on government spending in each sector ${ }^{2}$. Since $\omega^{N}>0$, we observe that when international capital inflows are spent in tradable sector $\left(\tilde{g}^{T}\right)$, this leads to a real exchange rate depreciation and vice-versa. The mechanisms behind these results are simple: when the government increases subsidies in the tradeable sector the demand for traded goods increase for a given stock of physical capital in the tradable sector. Consequently, the price of traded goods increases which leads to a depreciation of the real exchange rate. The mechanisms causing a real exchange rate appreciation following an increase in subsidies in the non-traded sector is the opposite.

Consider three international capital inflows in developing countries: foreign direct investment, foreign aid, and remittances. There is no disaggregated data on their allocation between the trading and the non-trading sectors even if we expect the first to mainly be spent on traded goods and the two-last on non-tradable goods. According to this model, the sign of the coefficients with respect to aggregate international capital inflows tells us on which sector they are more spent, i.e. whether they lead to an depreciation or appreciation of the real exchange rate.

3. The relative price channel or the Keynes effect: The effect of an improvement in terms-of-trade on the real exchange rate is ambiguous. Since $\rho \geq 0$, the effect of the terms-of-trade depends on the magnitude of $\gamma$ which is, the elasticity of substitution between all traded and non-traded goods. Generally, an increase in the terms-of-trade can be decomposed into a substitution and an income effect. Income effect consists of buying more goods as a result of increase in the terms-oftrade. The substitution effect is as follow: with an improvement in the terms-of-trade, the relative price of imported goods decreases with respect to the domestic tradable goods. This may lead to a decrease in demand for non-tradable goods, which reflects in the depreciation of the real exchange rate. Consequently, an improvement in the terms-of-trade lead to an appreciation of the real exchange rate if the income effect dominates the substitution effect. In this model, if the elasticity of substitution between traded and non-traded goods is high $(\gamma \geq 1)$ the substitution effect dominates the income effect, and an improvement in the terms-of-trade leads to an depreciation. Otherwise $(0 \leq \gamma<1)$ we have an appreciation of the real exchange rate.

How can an improvement in the terms-of-trade lead to Dutch disease? By increasing the production of traded goods, and consequently increasing income and spending. This leads to a higher production cost (through the mobility of factors) for non-traded goods, thus a rise in their prices: This is the Dutch disease "spending effect" (see Corden and Neary [1982], and Tokarick [2008]).

Equation (10) forms the basis for our empirical analysis.

\footnotetext{
${ }^{1}$ This show why it is not strong in this model to suppose that $\beta^{T}=\beta^{N}$ because the real exchange rate depends mainly on the allocations of labor and government spending between the two sectors not on capital allocation.

${ }^{2}$ Galstyan and Lane [2009] have relatively results. They show the importance of government spending on the real exchange rate. In their model, government consumption is associated with the real exchange rate appreciation and government investment leads to real depreciation of the RER
} 


\section{Estimation and Methodology}

\section{III.1 Data Sources}

We derived our data from the World Development Indicators (WDI, World Bank), the Penn World Table (PWT), and the Organization for Economic Cooperation and Development (OECD). Table III in the appendix summarizes our data sources and their definitions. The real exchange rate index is constructed in order to take into account the global competitiveness of each country. For a given country, this index is computed as a weighted average of different bilateral real exchange rates. The weight (coefficient) of each bilateral exchange rate is calculated based on the importance of the commercial partner, i.e. import plus export over GDP. An arithmetic average is used despite obvious drawbacks due to lack of data. The sample is composed of 39 countries with the annual data for the period $1970-2004$, so $N=39$ over $T=35$. Given the requirements for our econometric methodology we follow Loayza and Rancière [2006] and include only countries that have at least 20 consecutive observations. For this reason, our sample is restricted to 39 countries (see Table II for a complete list). Similar to Rogoff [1996] and Rodrik [2008], we use the gross domestic product per capita as a proxy for the Balassa-Samuelson effect. We also build a relative GDP in which USA is used as the point of reference. For the termsof-trade, we use the export to import percentage ratio unit value indexes, measured relative to the base year 2000. For foreign aid, we use the official development assistance (net disbursements) calculated by the OECD. We use the net FDI inflows as a percent of GDP calculated by the World Bank for Foreign direct investment and finally we use the percentage of workers' remittances, employee compensations, and migrant transfers over GDP in current USD for Remittances.

\section{III.2 A Descriptive Look at the Data}

Graphic 1 shows the evolution of our three capital inflow variables between 1970 and 2004. Since the beginning of the 1990s, we see a break in this trend: a rapid growing share of remittances and foreign direct investment in developing countries, more than $2 \%$ of their GDP and a less than $1 \%$ of GDP decline in foreign aid. In the appendix, we present bivariate scatterplots between the real exchange rate and its determinants in order to study the transfer problem descriptively. In a seminal paper ${ }^{1}$, Rogoff [1996] shows in an unconditional and cross-country analysis that the Balassa-Samuelson effect can account for $42 \%$ of the variation in the real exchange rate by using GDP per capita as the proxy of the BalassaSamuelson effect. From this, we should expect that a large part of the real exchange rate variation is accounted for through the Balassa-Samuelson effect. We run the same exercice as Rogoff [1996] with the other components of the real exchange rate in order to reveal their unconditional size.

Figure $3 \mathrm{e}$ shows the relationship between the logarithm of the real exchange rate and the logarithm of the foreign aid in 2004. It is clear from the figure that a rise in foreign aid results in a real exchange rate appreciation. Without other controls, this is what the Dutch disease theory predicts: capital inflows have negative impact on economic growth through the real exchange rate appreciation. If we try to understand the trend of the bivariate link between the RER and foreign aid (all years), we obtain figure 3 in the appendix. Panel (3b) of figure 3 depicts the link between the trend in foreign aid and the RER movements

${ }^{1}$ Rogoff Kenneth, (1996), “The Purchasing Power Parity Puzzle”, Journal of Economic Literature, Vol. 34, No 2, pp. 647-668. Page 15 of this paper contains the bivariate scatterplot (Figure 3) and the simple regression. 
(appreciation or depreciation). The former variable is computed using the coefficient of variation (standard deviation over the mean) in order to make the comparison across countries meaningful. This panel shows that the trend in foreign aid has no impact on the variation of the real exchange rate in LDCs and that the $R^{2}$ is zero. Panel (3d) of figure 3 seems to show that foreign aid variation can affect exchange rate movements even at very low levels and that the $R^{2}$ is equal to $2 \%$.

The same figure is depicted for the relationship between the real exchange rate and the remittances (figure (3f)). This panel shows that a rise in remittances is associated with a small real exchange rate appreciation (the curve is almost flat, the $R^{2}$ is equal to $1 \%$ ). In theory, remittances are associated with an exchange rate appreciation due to the fact that they are mainly spent on non-tradable goods (Stahl and Arnold [1986]). The same operation is done by using other fundamentals than capital inflows. Panel (a) and panel (c) in figure 5 show the relationship between the exchange rate variations and the termsof-trade. In term of methodology, Panel (a) is directly comparable to the Rogoff's result. By contrast to foreign aid, this figure seems to show that the trend in the terms-of-trade is correlated to exchange rate movements and that the $R^{2}$ is equal to $11 \%$ (panel (a)). Without other control variables, the effect of capital inflows on exchange rate movements does not appear to be very strong in the LDCs.

The unconditional analysis suggests the main determinant of the real exchange is the Balassa-Samuelson effect, the second determinant seems to be the channel highlighted by Keynes, i.e. the terms-of-trade channel. The unconditional analysis also suggests that the channel highlighted by Yano and Nugent should be very weak. This contradicts the theory presented above, especially equation (10), which suggests that the three channels must affect the real exchange rate. Consequently, a more careful econometric analysis is required than this simple descriptive analysis.

\section{III.3 Prediction derived from the theoretical model}

Equation (10) contains the main result of the paper: The real exchange rate can be written as a function of terms-of-trade, productivity differential, and international transfers. We implement it empirically as:

$$
\begin{aligned}
\ln \operatorname{RER}_{i, t} & =\beta_{0}+\mu_{i}+\delta_{t}+\epsilon_{i, t} \\
& +\underbrace{\beta_{1} \ln \left(\frac{\mathrm{AID}_{i, t}}{\mathrm{GDP}_{i, t}}\right)+\beta_{2} \ln \left(\frac{\operatorname{Remittances}_{i, t}}{\mathrm{GDP}_{i, t}}\right)+\beta_{3} \ln \left(\frac{\mathrm{FDI}_{i, t}}{\mathrm{GDP}_{i, t}}\right)}_{\text {Yano and Nugent or Transfer effect }} \\
& +\underbrace{\beta_{4} \ln \left(\mathrm{TOT}_{i, t}\right)}_{\text {Keynes or TOT effect }}+\underbrace{\beta_{5} \ln \left(\text { Productivity differential }_{i, t}\right)}_{\text {Balassa-Samuelson effect }}
\end{aligned}
$$

where $t=1,2 \cdots T, i=1,2 \cdots N, \mu_{i}$ is a country fixed effect and $\delta_{t}$ is time fixed effect.

Most studies on the Dutch disease - transfer problem - used panel data and implement directly the above equation without any theoretical background. The goal of the theoretical section was to build a microfoundation of the equation (11). This provides a view of the channels through which the different types of capital inflows affect the real exchange rate; it also help to interpret the results and to better identify the empirical factors driving the real exchange rate. The goal of the empirical part is to implement it correctly. 


\section{III.4 Pitfalls when studying exchange rates}

In the introduction, we highlighted four reasons or combinations that result in diverse outcomes for the effect of capital inflows on the real exchange rate.

1. the estimation methods in some studies are weak

2. the inadequate estimation methods for the subject

3. the papers focus on the sign of the effect rather than its size

4. the absence of micro-foundation which helps interpret the results

We used section II to address the fourth issue. Section III.7 will address the third issue. The current and the next sections address the two first issues. Before starting to test and implement the main equation of the paper, we highlight some pitfalls. We consider three important pitfalls: the heterogeneity of countries in the panel, the non-stationary nature of most macroeconomic variables and the dynamic nature of the real exchange rate.

Heterogeneity remains an unresolved issue despite panel data techniques: In general panel literature and in particular literature on the Dutch disease, heterogeneity has never been treated appropriately. Cross-country comparisons must explicitly take heterogeneity into account. Standard panel estimators that homogenize countries produce very biased results (Pesaran and Smith 1995). The main goal of our study is to assess the impact of capital inflows on LDCs real exchange rates. By assuming PPP, the RER is the relative price of tradable and non-tradable goods. In this case not only the relative price between countries is different, but also between sectors within a country. These disparities are a consequence of substitutability, tradability and transport cost differences Imbs, Mumtaz, Ravn, and Rey [2005].

Models of exchange rates must take its dynamics into account: Another problem that is often ignored by the literature is the dynamics of the real exchange rate in developing countries. In fact, despite many countries having fixed nominal exchange rates their real exchange rates are nevertheless subject to huge variations due to large inflation movements. We must take into account the convergence of each RER toward its PPP. The main method used to deal with this problem, is to introduce lagged variables of the independent variable in the specification of the real exchange rate. This creates a new endogeneity and consequently a new source of bias. However, these lagged variables need to be introduced on the explained variables in order to compute the rate of exchange rates convergence toward their equilibrium values (Rogoff [1996]). Standard panel techniques (fixed effect or compound errors) do not solve these problems (Pesaran and Smith [1995]). One way to do this is to use GMM techniques à la Arellano and Bond [1991]. But even in this case, under the heterogeneity assumption, estimated coefficients are biased (Imbs, Mumtaz, Ravn, and Rey [2005]).

Stationarity is a convenient assumption but often leads to spurious results: The last problem that we discuss is the non-stationarity of most macroeconomic time series. As noted by Nelson and Plosser [1982], most economic time series are non-stationary and use classical econometric techniques that assume data stationarity, leads to spurious regression results.

The main contribution of the empirical part consists of the application of recent advances in time series and panel econometrics in order to link capital inflows and real exchange rates. The strength of our conclusions depends mainly on the explicit consideration of sample heterogeneity, the dynamics and the non-stationarity of our variables. 


\section{III.5 Pesaran, Shin, and Smith [1999] Solution's}

Table IV and table VI show that our variables are not stationary (see the appendix for a more detailed explanation of the stationarity tests). Standard econometric techniques would give biased results when data are non-stationary (Granger and Newbold [1974]). However in the last few years, most time series techniques have been adapted into panel econometric methodology. For the stationarity problem, Pesaran, Shin, and Smith [1999] propose a flexible estimator for panels because it allows for estimated stationary and non-stationary data. This estimator also allows us to take into account the heterogeneity problem. Formerly, econometricians took care of heterogeneity by estimating each unity of the panel separately before estimating an unweighted average of coefficients. This is known as the Mean Group (MG) estimator, Pesaran and Smith [1995]. Another method, the Dynamic Fixed Estimator (DFE) imposes a parameter homogeneity both in the short and the long run. Pesaran, Shin, and Smith [1999] propose a more flexible method: the Pooled Mean Group (PMG) estimator. They impose the long term parameters to be the same and allow short term and convergence coefficients to vary across the different units of the panel. Under the assumption of long term coefficient homogeneity, PMG offers a more efficient estimator than MG. With the Hausman's test, it is also possible to check if the assumption of long term parameters homogeneity is restrictive or not.

We simplify the PMG estimator and write our equation of interest as (see Pesaran, Shin, and Smith [1999] for a more formal treatment):

$$
\operatorname{rer}_{i, t}=\sum_{j=1}^{q} \beta_{i, j} X_{i, j, t}+\mu_{i}+\varepsilon_{i, t}
$$

where $t=1,2 \cdots T, i=1,2 \cdots N, \mu_{i}$ is a country fixed effect and $X_{i t}$ is a set of control variables. In this form, the model is not different from fixed effect panel methodology. To introduce dynamics, an unrestricted AutorRegressive Distributed Lag (ARDL) is added $(p, q \cdots q)$ where $p$ is the number of lags of the explained variable and $q$ is the number of lags of different explanatory variables. So the above equation can be written as:

$$
\operatorname{rer}_{i, t}=\sum_{j=1}^{p} \alpha_{i} \operatorname{rer}_{i, t-j}+\sum_{j=1}^{q} \beta_{1 i, j} X_{i, j, t}+\sum_{j=1}^{q} \beta_{2 i, j} X_{i, t-j}+\mu_{i}+\varepsilon_{i, t}
$$

When this equation is rewritten in a form of Vector Error Correcting Model (VECM) by imposing long term parameters to be the same and allowing short term and convergence coefficients to vary across the different units of the panel, we have the following equation:

$$
\Delta r e r_{i, t}=\phi_{i}\left(\operatorname{rer}_{i, t-1}-\theta_{0 i}-\sum_{j=1}^{q} \beta_{i, j} X_{i, j, t-1}\right)-\sum_{j=1}^{q} \beta_{2 i, j} \Delta X_{i, j, t}+\varepsilon_{i, t}
$$

where the terms in parenthesis are long term coefficients. If we impose only one lag for each variable, we can identify the parameters of interest. The coefficient of adjustment $\phi$ is given by $\phi_{i}=-\left(1-\alpha_{i}\right)$ and the long term coefficients are $\theta_{0 i}=\mu_{i} /\left(1-\alpha_{i}\right)$ and $\beta_{i, j}=\left(\beta_{1 i, j}+\beta_{2 i, j}\right) /\left(1-\alpha_{i}\right)$. The Pooled Mean Group estimator imposes equality of the $\beta_{i, j}$ across countries, i.e. $\beta_{i, j}=\beta_{j}$ for all countries. 
Consequently, the estimated equation is:

$$
\Delta \operatorname{rer}_{i, t}=\phi_{i}\left(\operatorname{rer}_{i, t-1}-\theta_{0 i}-\sum_{j=1}^{q} \beta_{j} X_{i, j, t-1}\right)-\sum_{j=1}^{q} \beta_{2 i, j} \Delta X_{i, j, t}+\varepsilon_{i, t}
$$

with $\beta_{2 i, j}$, the short-run coefficients. ${ }^{1}$.

\section{III.6 Estimation Results}

The methodology described above is applied in order to explain the determinants of real exchange rate movements. Effects of each variable in the short and long run are computed. The results are presented in tables VII and VIII. We focus on the results from the Pooled Mean Group (PMG) estimator since the Dynamic Fixed Effect (DFE) gives theoretically and empirically biased results under heterogeneity assumption. We also do not present the results of the Mean Group (MG) estimator due to the fact that the Hausman's test allows us to disentangle the choice between these two estimators. The first column in table VII is the real exchange rate regression with respect to all variables, the second column in the regression on capital inflows variables - foreign aid, remittances and foreign direct investment - and the last column is the regression of the real exchange rate on real fundamentals (relative gross domestic product per capita and terms-of-trade).

Column 1 in table VII contains the main results of this work. The Hausman's test shows that we cannot reject the hypothesis of long run homogeneity, which means that the PMG estimator is more efficient than the MG estimator. For the proxy of the Balassa-Samuelson effect, a rise in GDP per capita causes a real exchange depreciation in the short run and in the long run. For the terms-of-trade, these increases also cause a depreciation in the short run and in the long run. So, for these countries the substitution effect dominates the income effect in the short and in the long run. If we compare the results for the terms-of-trade with the discussion in section II.5, we can deduce that for these countries, the channel identified by Keynes [1929] works as expected, i.e. the improvement in their terms-of-trade did not lead to a Dutch disease.

For the variables of interest (capital inflows), all of them impact significantly the real exchange rate: foreign aid and foreign direct investment are associated with an exchange rate appreciation in the short and in the long runs, which means that the transfer problem theory is validated. Below, we will explain how big their effects are compared to other fundamentals. Furthemore, remittances are only associated with a real exchange rate appreciation in the short run. If we try to understand the role of the capital inflows as the only main determinants of the real exchange rate (Column 2 Table VII) the same results hold except that the homogeneity of the long run capital inflows elasticities are rejected because of the Hausman's test. This means that the impact of capital inflows on the real exchange rate is heterogeneous

\footnotetext{
${ }^{1}$ Another advantage of the Pooled Mean Group estimator is that we do not need variables to be co-integrated. The former time series literature (Johansen [1996]) required not only variables to be non stationary but also to be co-integrated in order to have long-run relationships between variables. The method proposed by Pesaran, Shin, and Smith [1999] does not require the co-integration between variable. The PMG estimator handles both co-integration and no co-integration. In equation (12), if $X$ is weakly exogenous, then co-integration requires $\phi(i) \neq 0$. If there is no co-integration relationship, $\phi(i)=0$ and we have a first difference model. Since the $\phi(i)$ is country specific in our case, the PMG allows both cases. So the methodology presented in section III.5 gives consistent and efficient estimates. See Pesaran Hashem, Shin Yongcheol, and Smith Richard, "Bounds testing approach to the analysis of levels relationships", Journal of Applied Econometrics, 2001, for more details. We appreciate Ron P. Smith for his helpful advices on this matter
} 
in developing countries. Another important result is the long adjustment time to reach its long term value (-0.15), which emphasizes the persistence of the RER in LDCs.

Comparing these results with the existing literature, reveals some interesting features. One of the papers that uses cross-country panels to study the Dutch disease is Lartey [2007] and Nwachukwu [2008] that focus on Sub-Saharan Africa. The first paper examined the capital inflows in a disaggregated way by using GMM à la Arellano and Bond [1991]. It concludes that foreign aid caused an exchange rate overvaluation, i.e. an increase in foreign aid by $1 \%$ lead to an appreciation of the real exchange rate by $0.1 \%$. Another paper that also reaches the same conclusion using the same technique is by Ouattara and Strobl [2008]. They examined the link between foreign aid and real exchange rate in the CFA zone in the short run and concluded that there is no Dutch disease. A $10 \%$ increase in the foreign aid is associated with an increase of only $1 \%$ in the real exchange rate in the short-run. Rajan and Subramanian [2011] reached the same conclusion in a seminal paper. However it is difficult to compare our results with this latter paper. They used an approach that was more microeconomic by looking into a manufacturing panel for a number of different countries. They found that foreign aid causes a loss in competitiveness through real exchange rate appreciation, which penalizes the export sectors, especially manufacturing industries.

If we also compare the results of the PMG estimator (Table VII) with those obtained by the DFE estimator (Table VIII), we can see how the last one gives biased results. DFE is the generalization of the Fixed Effects (FE) estimator. Therefore it takes into account only the dynamics and not the nonstationarity. Under heterogeneity assumptions, this result in inconsistent estimates. This is clear by looking at the different result between the PMG estimator and the DFE. This discussion also emphasizes the limitations of previous studies, which directly use traditional panel data techniques (fixed effects or error components).

Even if the computation of elasticities and the discussion of their significance are important, they are not useful for economic policy. Following Soto and Elbadawi [2007], it is now common to compute the implied net effect. The results of our previous analysis is checked by computing the implied net effect of each determinants of the exchange rate movements. This is the product of the estimated long run coefficient and the standard deviation, so we focus on the impact of one standard deviation change on the level of the variable. For the PMG estimator, we use long run elasticities. The result is depicted in figure 2. It shows the fact that capital inflows have a low impact on exchange rate movements even if they impact then significantly in a statistical meaning. The main variables which explain real exchange rate variations in developing countries are the Balassa-Samuelson effect and the Keynes effect.

The unconditional analysis in section III.2 goes against the theory presented in section II because it suggested that the channel highlighted by Yano and Nugent [1999], the relative quantity channel, should be weak. The conditional analysis confirms this result. The results state that in order to understand the link between capital inflows and growth, the Dutch disease channel described by Yano and Nugent [1999] can be neglected due to the simple fact that in developing countries, foreign aid, foreign direct investment and remittances are poor explanations of their real exchange rates.

\section{III.7 Robustness analysis}

The main finding of the empirical part is that the transfer problem through capital inflows exists but its effect on the real exchange rate is weak compared to others fundamentals like the gross domestic product per capita or the terms-of-trade. In order to check this once again, we do a variance decomposition of the real exchange rate. In other words, in the variance of the real exchange rate, we look at the explained 
share by each variable. To do so, we run a Panel Vector AutoRegression (PVAR) of order three. The most general form of the model can be written as:

$$
\Pi_{i, t}=\mu_{i}+\Theta(L) \Pi_{i, t-1}+\epsilon_{i, t}, i=1, \cdots, N, t=1, \cdots, T
$$

where $\Pi_{i, t}$ contains six variables in the following ordering: real exchange rate, gross domestic product per capita, terms-of-trade, foreign aid, foreign direct investment, and remittances. $\mu_{i}$ is the country idiosyncratic effect, $\epsilon_{i, t}$ is the residual error and $\Theta(L)$ is a lag operator with $\Theta(L)=\Theta_{1} L+\Theta_{2} L^{2}+$ $\cdots \cdots+\Theta_{p} L^{p}$. In order to compute impulse response functions (IRF) properly, we identify the shocks using the Choleski decomposition. This decomposition introduces some restrictions on contemporaneous correlations between variables. The Cholesky decomposition assumes that in the ranking of the variables, the first one is the more exogenous while the last one is the more endogenous. In other words, the first variable can affect the last variable while the opposite is not possible. Since the focus of this paper is the effect of capital inflows (foreign aid, foreign direct investment, and remittances) on the real exchange rate, we consider them to be more endogenous compared to the other two real variables, namely the productivity differential and the terms-of-trade. So ordering is more between nominal versus real variable than between variables in each group. PVAR methodology is also useful for taking into account the endogeneity problem and the interactive dynamics between variables. Helmert's transformation is used in order to remove the individual effects, i.e. the difference between each variable and its forward mean. The result of the variance decomposition is summarized in table I. According to this table, the terms-of-trade and the gross domestic product are the main factors that explain the variations in the real exchange (appreciation or depreciation). Capital inflows account for 19\% of the RER variation in developing countries. In other words, using various recent econometric techniques does not change the results: the transfer problem caused by capital inflows exists but its effect on the real exchange rate in developing countries is not very strong.

Table I: Variance decomposition of RER in LDCs - 1970-2004

\begin{tabular}{|c|c|c|c|c|}
\hline \hline B-S Effect & TOT & Foreign aid & FDI & Remittances \\
\hline $57 \%$ & $24 \%$ & $9 \%$ & $9 \%$ & $1 \%$ \\
\hline
\end{tabular}

Source: Authors' calculation using a PVAR(3)

\section{Conclusion}

The findings in this paper suggest that capital inflows explain a small share of exchange rate movements in less developed countries. The goal of this paper was to study the effect of capital inflows such as foreign aid, remittances and foreign direct investment on the real exchange rate movements in developing countries. Dutch disease theory states that foreign aid impacts growth negatively through an appreciation of the real exchange rate. We studied a certain form of Dutch disease: the transfer problem and we decomposed the exchange rate variation by the variation of its individual components. Using techniques recently developed in time series and panel data econometrics, we disentangled exchange rate variations from variations caused by capital inflows, terms-of-trade, and productivity differentials.

Roughly $19 \%$ of real exchange variation in developing countries can be explained by capital inflows 
while the remaining part identified by J. M. Keynes, B. Balassa, and P. A. Samuelson. Thus, our results do not reject the transfer problem theory, but estimate that its impact on the real exchange appreciation or depreciation is low compared to other factors that affect the real exchange rate in developing countries. We believe that this finding is important because the transfer problem literature exhibits contradictory results. A number of empirical studies have concluded that capital inflows such as foreign aid are associated with real exchange rate appreciation, others found the opposite. Our final result is that no matter the sign, the size is not very big.

\section{Appendix}

\section{IV.1 Constants of the model}

The details of the model's calculation are available in the online appendix. Here are the constants stated in in the model.

$$
\begin{aligned}
& \mathrm{A}=\gamma^{-\gamma}(1-\gamma)^{-(1-\gamma)} \\
& B=A^{-1}\left[1+\frac{\gamma}{1-\gamma} \frac{1}{1-\rho}+\frac{\rho}{1-\rho}\right]\left(\frac{\rho}{1-\rho}\right)^{-\rho(1-\gamma)}\left(\frac{\gamma}{1-\gamma}\right)^{-\gamma}\left(\frac{1}{1-\rho}\right)^{-\gamma} \\
& C=\left(\frac{k^{T}}{z^{T}}\right)^{\frac{\alpha^{T}}{\beta^{T}}-\frac{\alpha^{N}}{\beta^{N}}}=\frac{\tilde{\beta}\left(1-\alpha^{T}\right)}{1-\tilde{\beta}(1-\delta)}
\end{aligned}
$$

\section{IV.2 Data description}

Table II: Sample of countries

Algeria, Argentina, Bolivia, Botswana, Brazil, Burkina Faso, Chile, Colombia, Congo Republic, Ecuador, Egypt, El Salvador, Gambia, Guatemala, Haiti, Honduras, Indonesia, Iran, Jamaica, Kenya, Madagascar, Malawi, Malaysia, Mexico, Morocco, Nicaragua, Niger, Nigeria, Pakistan, Panama, Paraguay, Peru, Philippines, South Africa, Sri Lanka, Togo, Tunisia, Uruguay, Venezuela. 
Table III: Data Sources and Definitions

\begin{tabular}{|c|c|c|}
\hline Variables & Definitions & Sources \\
\hline Foreign Aid & Ratio of aid to GDP & Development Assistant Committee \\
\hline GDP per capita & $\begin{array}{l}\text { GDP per capita } \\
\text { relative to USA }\end{array}$ & $\begin{array}{l}\text { Penn World Table } 6.2 \text { (PWT 6.2) } \\
\text { and authors's calculations }\end{array}$ \\
\hline terms-of-trade & $\begin{array}{l}\text { Ratio of export price } \\
\text { to import price }\end{array}$ & World Development Indicators 2006 \\
\hline Real Exchange Rate & $\begin{array}{l}\text { Ratio of exchange rate } \\
\text { to PPP conversion factors }\end{array}$ & Penn World Table 6.2 (PWT 6.2) \\
\hline Real Exchange Rate Index & $\begin{array}{l}\text { Arithmetic weighted } \\
\text { average }\end{array}$ & Author's construction using PWT 6.2 \\
\hline Foreign Direct Investment & $\begin{array}{l}\text { Ratio of net FDI } \\
\text { to GDP }\end{array}$ & World Development Indicators 2006 \\
\hline Remittances & $\begin{array}{l}\text { Worker's remittances and } \\
\text { migrant transfers }\end{array}$ & $\begin{array}{l}\text { BoP Statistics (IMF), WDI } 2006 \text { and } \\
\text { and authors's calculations }\end{array}$ \\
\hline
\end{tabular}

\section{IV.3 Panel Unit Roots Tests used in the paper}

We use three tests to check whether our variables are stationary or not. The two first are among the first generation and the third, among the second generation.

Levin, Lin, and James Chu [2002] test is among the first generation of stationarity tests of panel data. Define $y_{i t}$ such that $i=1, \cdots, N$ and $t=1, \cdots, T$ where $i$ and $t$ are individual and time dimension. Levin, Lin and Chu (2002, page 4) consider that the data generating process of $y_{i t}$ is one of the following three models:

$$
\begin{aligned}
& \text { Model } 1 \Delta y_{i t}=\delta y_{i, t-1}+\varepsilon_{i t} \\
& \text { Model } 2 \Delta y_{i t}=\alpha_{0 i}+\delta y_{i, t-1}+\varepsilon_{i t} \\
& \text { Model } 3 \Delta y_{i t}=\alpha_{0 i}+\alpha_{i, t}+\delta y_{i, t-1}+\varepsilon_{i t}
\end{aligned}
$$

where $\varepsilon_{i t}$ are the error terms that follow an ARMA process, $\varepsilon_{i t}=\sum_{j=0}^{\infty} \varepsilon_{i, t-j}+\zeta_{i t}$. So, in this test, the idiosyncratic constant $\left(\alpha_{0 i}\right)$ and the trends $\left(\alpha_{i, t}\right)$ vary across individuals. The procedure of the test is sequential and goes from general to specific. The general model is

$$
\Delta y_{i t}=\delta y_{i, t-1}+\sum_{L=1}^{P_{i}} \theta_{i L} \Delta y_{i, t-L}+\alpha_{m i} d_{m t}+\varepsilon_{i t}, m=1,2,3 .
$$

and the statistic of the test is

$$
L L C=\sqrt{1.25}\left[t_{\delta}-\frac{\sqrt{N} \varphi_{1 T}}{\sqrt{\varphi_{2 T}}}\right]
$$

with $t_{\delta}=\frac{\hat{\delta}}{\hat{\sigma}_{\delta}}, \varphi_{1 T}=-\frac{1}{2}-\frac{1}{2} T^{-1}$ et $\varphi_{2 T}=\frac{1}{6}+\frac{5}{6} T^{-2}$

Non-stationarity is tested versus stationarity: 


$$
H_{O}: \delta=0 \mathrm{VS} H_{A}: \delta<0
$$

Im, Pesaran, and Shin [2003]: this test is an extension of the ADF test in a panel context. Let $y_{i t}$ be the variable for which we want to test for stationarity. The general model can be written as:

$$
\Delta y_{i, t}=\mu_{i}+\alpha_{i} t+\rho_{i} y_{i, t-1}+\sum_{j=1}^{p} \phi_{i j} \Delta y_{i, t-j}+\varepsilon_{i, t}
$$

while the previous test considered that $\rho$ is homogeneous across countries, the IPS estimates each panel separately and computes the average of individual statistics, i.e., $t-\operatorname{bar}_{N T}=\frac{1}{N} \sum_{i=1}^{N} t_{i T}$.

Under the null hypothesis, the authors show that the statistic of the test is (Im, Pesaran, and Shin [2003], page 6.)

$$
Z_{t b a r}=\frac{\sqrt{N}\left(\operatorname{tbar}_{N T}-N^{-1} \sum_{i=1}^{N} E\left(t_{T_{i}}\right)\right)}{\sqrt{N^{-1} \sum_{i=1}^{N} \operatorname{Var}\left(t_{T_{i}}\right)}} \Longrightarrow N(0,1)
$$

null hypothesis is the non-stationarity

$$
H_{O}: \rho_{i}=0 \forall \mathrm{i} V S H_{A}: \rho_{i}<0 \forall \mathrm{i}
$$

\begin{tabular}{|c|c|c|c|c|c|}
\hline \multicolumn{6}{|c|}{ Levels: with intercept and trend } \\
\hline variables & LLC (t-val.) & IPS (t-bar) & & O-I & \\
\hline $\log (\mathrm{RER})$ & -21.67 & -1.922 & & $\mathrm{I}(1)$ & \\
\hline $\log ($ Aid $)$ & -22.60 & -2.002 & & $\mathrm{I}(1)$ & \\
\hline $\log ($ TOT $)$ & -14.37 & -1.805 & & $\mathrm{I}(1)$ & \\
\hline $\log (\mathrm{FDI})$ & -29.20 & -2.533 & & $\mathrm{I}(1)$ & \\
\hline $\log (\mathrm{GDP})$ & -14.05 & -0.971 & $\mathrm{I}(0)$ & or & $\mathrm{I}(1)$ \\
\hline \multicolumn{6}{|c|}{ First differences: with intercept } \\
\hline variables & LLC (t-val.) & IPS (t-bar) & & O-I & \\
\hline$\Delta(\mathrm{RER})$ & -32.63 & -2.673 & & $\mathrm{I}(1)$ & \\
\hline$\Delta($ Aid $)$ & -39.06 & -3.320 & & $\mathrm{I}(1)$ & \\
\hline$\Delta(\mathrm{TOT})$ & -40.16 & -3.572 & & $\mathrm{I}(1)$ & \\
\hline$\Delta(\mathrm{FDI})$ & -48.81 & -4.064 & & $\mathrm{I}(1)$ & \\
\hline$\Delta(\mathrm{GDP})$ & -16.34 & -1.426 & $\mathrm{I}(0)$ & or & $\mathrm{I}(1)$ \\
\hline
\end{tabular}

The following figure gives the results of the different panel unit root tests. All variables are tested in level and in difference, with trend and without trend.

Table IV: Panel Unit Root Test: LLC \& IPS

Note: For IPS and LLC panel unit root tests, the $5 \%$ critical value is - 1.645.

Pesaran [2007]: for many years ago, researchers have paid too much attention to the problem of unit root tests in heterogeneous panels and assume that each time-series is independent from other crosssection time series in the panel. Many studies have proposed new panel unit root tests to overcome this problem. 
The one we use here is proposed by Pesaran [2007]. The suggested estimator in this article is crosssection augmented ADF or CADF. It is the cross-section averages of lagged levels and first difference of the individual series. A truncated version of the test is also used where the individual CADF statistics are suitably truncated to avoid undue influences of extreme outcomes that could arise when $T$ is small (10-20).

Specifying the null-hypothesis: Let $y_{i t}$ be the observation on the $i$ th cross section unit at time $t$ and suppose that it is generated by the following process

$$
y_{i t}=\left(1-\phi_{i}\right) \mu_{i}+\phi_{i} y_{i, t-1}+u_{i t}, \quad i=1, \ldots, N ; \quad t=1, \ldots, T
$$

The error term has the single factor structure:

$$
u_{i t}=\gamma_{i} f_{t}+\sigma_{i t}
$$

Equations (13) and (14) can be combined as follow

$$
\Delta y_{i t}=\alpha_{i}+\beta_{i} y_{i, t-1}+\gamma_{i} f_{t}+\varepsilon_{i t}
$$

where $\alpha_{i}=\left(1-\phi_{i}\right) \mu_{i}, \beta_{i}=-\left(1-\phi_{i}\right)$ and $\Delta y_{i t}$ is the first difference. The null hypothesis is therefore

$$
H_{0}: \beta_{i}=0 \text { for all } i
$$

against

$$
H_{1}: \beta_{i}<0 \quad i=1,2, \ldots, N_{1}, \beta_{i}=0, i=N_{1}+1, N_{1}+2, \ldots, N
$$

However the test is based on the $t$-ratio of the OLS estimate of $b_{i}$ in the following cross-sectionally augmented DF (CADF) regression:

$$
\Delta y_{i t}=a_{i}+\beta_{i} y_{i, t-1}+c_{i} \bar{y}_{t-1}+d_{i} \Delta \bar{y}_{t}+e_{i t}
$$

The limit distribution of the $t$-ratio is given in Pesaran [2007]. This is also the CADF statistic used in the test. In addition, critical values for the test for different cases, including one with intercept and one with trend and intercept, are shown in tables I to III in the article. Since the CADF statistic is asymptotically independent from the nuisance parameter, one possibility would be to consider a cross sectionally augmented version of the IPS test based on

$$
C I P S(N, T)=t-\text { bar }=\frac{1}{N} \sum_{i=1}^{N} t_{i}(N, T)
$$

in which $t_{i}(N, T)$ is the $i$ th cross-section $t$-ratio of the coefficient of $y_{i, t-1}$ in the CADF regression defined in (18). The IPS statistic is:

$$
I P S(N, T)=\frac{\sqrt{N}\left\{t-\operatorname{bar}_{N T}-E\left[t_{i T} \mid \beta_{i}=0\right]\right\}}{\sqrt{\operatorname{var}\left[t_{i T} \mid \beta_{i}=0\right]}} \Rightarrow N(0,1)
$$

where $t-\operatorname{bar}_{N T}=N^{-1} \sum_{i=1}^{N} t_{i T}$ and $t_{i T}$ is the $t$-ratio of the estimated coefficient of $y_{i, t-1}$ in the OLS regression of $\Delta y_{i t}$ on an intercept and $y_{i, t-1}$. 
The above tests can be generalized for higher-order processes. For example, for an $A R(p)$ the relevant individual CADF will be given by the OLS $t$-ratio of $b_{i}$ in the following $p$ th order cross-section augmented regression:

$$
\Delta y_{i t}=a_{i}+\beta_{i} y_{i, t-1}+c_{i} \bar{y}_{t-1}+\sum_{j=0}^{p} d_{i j} \Delta \bar{y}_{t-j}+\sum_{j=1}^{p} \delta_{i j} \Delta \bar{y}_{i, t-j}++e_{i t}
$$

However it is useful to look at the cross-section dependence (CD) test statistics proposed by Pesaran [2007]. The CD statistic is

$$
C D=\left(\frac{T N(N-1)}{2}\right)^{1 / 2} \overline{\hat{\rho}}
$$

where

$$
\overline{\hat{\rho}}=\left(\frac{2}{N(N-1)} \sum_{i=1}^{N-1} \sum_{j=i+1}^{N} \hat{\rho}_{i j}\right)
$$

and $\hat{\rho}_{i j}$ is the pair-wise cross-section correlation coefficients of the residuals from these regressions. The null-hypothesis is zero dependence $\left(\gamma_{i}=0\right)$. The CD test is carried out at the 5\% 2-sided nominal significant level. The null is rejected if $|C D| \geqslant 1.96$.

The $\mathrm{CD}$ test statistics are reported in table V:

Table V: CD statistics for the log value and first difference of variables

\begin{tabular}{lrrrrr}
\hline CD/Variables & $\ln ($ RER $)$ & $\ln ($ Aid $)$ & $\ln$ (TOT) & $\ln$ (FDI) & $\ln (\mathrm{GDP})$ \\
\hline$p=1$ & 14.38 & 6.67 & 10.75 & 5.65 & 7.51 \\
$p=2$ & 10.83 & 7.05 & 10.79 & 4.67 & 6.81 \\
$p=3$ & 10.86 & 6.86 & 9.73 & 4.49 & 7.22 \\
$p=4$ & 11.25 & 5.74 & 9.26 & 4.90 & 6.18 \\
\hline CD/Variables & $\Delta($ RER $)$ & $\Delta(\mathrm{Aid})$ & $\Delta(\mathrm{TOT})$ & $\Delta(\mathrm{FDI})$ & $\Delta(\mathrm{GDP})$ \\
\hline$p=1$ & 7.99 & 5.42 & 10.74 & 2.88 & 7.14 \\
$p=2$ & 8.18 & 5.69 & 7.52 & 3.9 & 7.72 \\
$p=3$ & 7.84 & 5.76 & 8.45 & 3.98 & 6.17 \\
$p=4$ & 7.11 & 6.5 & 8.6 & 4.58 & 6.81 \\
\hline
\end{tabular}

As shown above, the null hypothesis is rejected for all variables with first to forth order of generating process. Therefore the IPS and the LLC statistics reported in table IV should be revised. In this case we should consider the CIPS test that allows for cross-section dependence. 
Table VI: Panel unit root test with cross-section dependency using CIPS statistics for the log value and first difference of variables with intercept

\begin{tabular}{lrrrrr}
\hline CIPS/Variables & $\ln ($ RER) & $\ln$ (Aid) & $\ln$ (TOT) & $\ln$ (FDI) & $\ln (\mathrm{GDP})$ \\
\hline$p=1$ & -2.19 & -2.297 & -3.074 & -3.667 & -1.716 \\
$p=2$ & -2.283 & -2.033 & -3.075 & -2.785 & -2.028 \\
$p=3$ & -2.104 & -1.824 & -2.754 & -2.515 & -1.782 \\
$p=4$ & -2.299 & -1.728 & -2.543 & -2.266 & -1.791 \\
\hline CIPS/Variables & $\Delta$ (RER) & $\Delta$ (Aid) & $\Delta($ TOT $)$ & $\Delta($ FDI) & $\Delta($ GDP $)$ \\
\hline$p=1$ & -5.093 & -6.288 & -5.279 & -7.136 & -4.638 \\
$p=2$ & -4.068 & -4.396 & -4.559 & -4.843 & -3.732 \\
$p=3$ & -2.843 & -3.563 & -3.929 & -4.122 & -2.922 \\
$p=4$ & -2.724 & -3.209 & -3.509 & -3.364 & -2.564 \\
\hline
\end{tabular}

Table VI shows the result for the CIPS statistics. The critical values for this test are calculated in table II of Pesaran [2007]. The critical value of the CIPS statistic for $N=38$ and $T=34$ is around -2.14 . Therefore according to the CIPS test the null hypothesis of the unit root can be rejected at $5 \%$ level irrespective of the value of $p$ for all variables except $\ln (\mathrm{GDP})$.

These results show that in order to investigate transfer problems in the LDCs countries, the nonstationarity of these variables should be considered. 


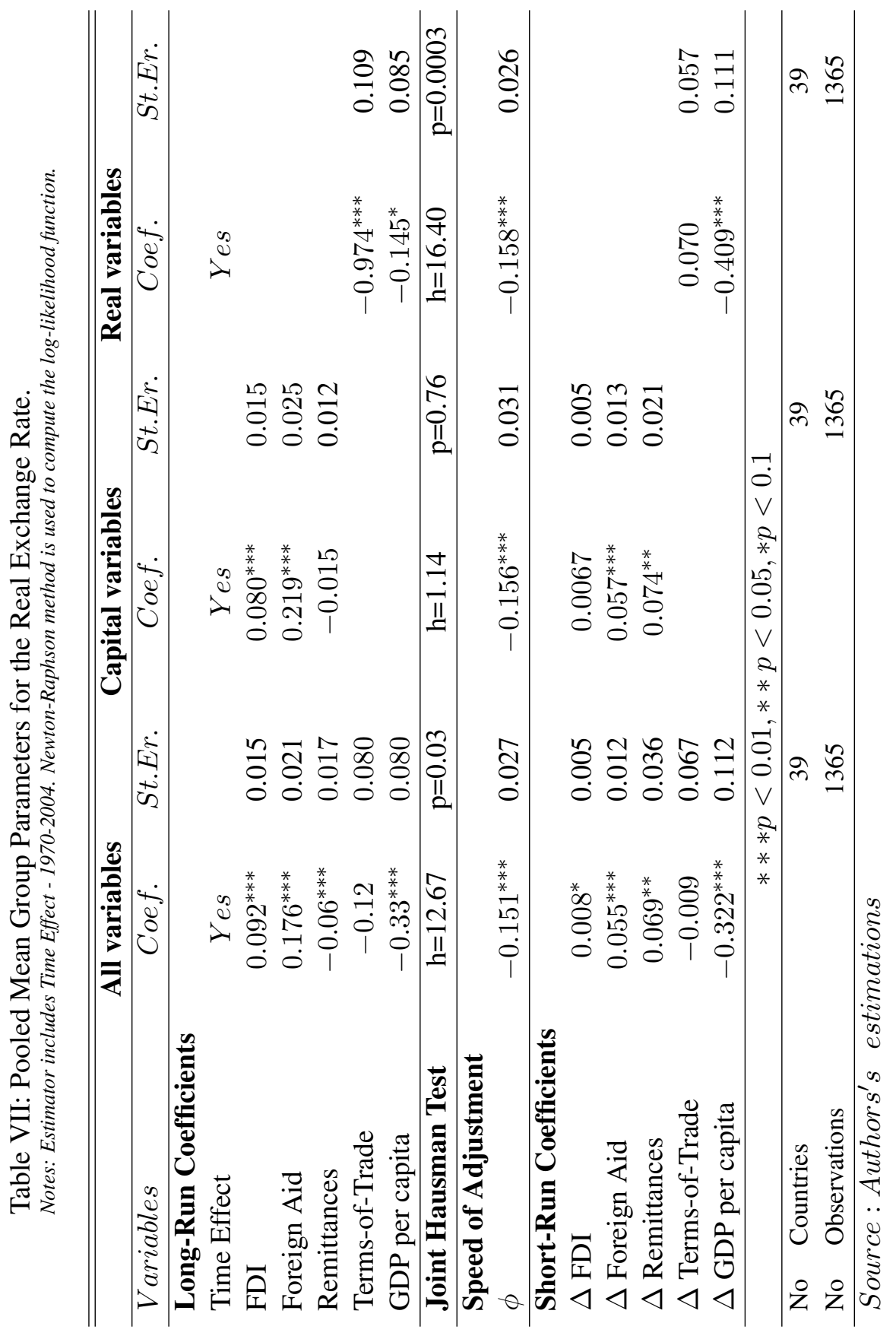




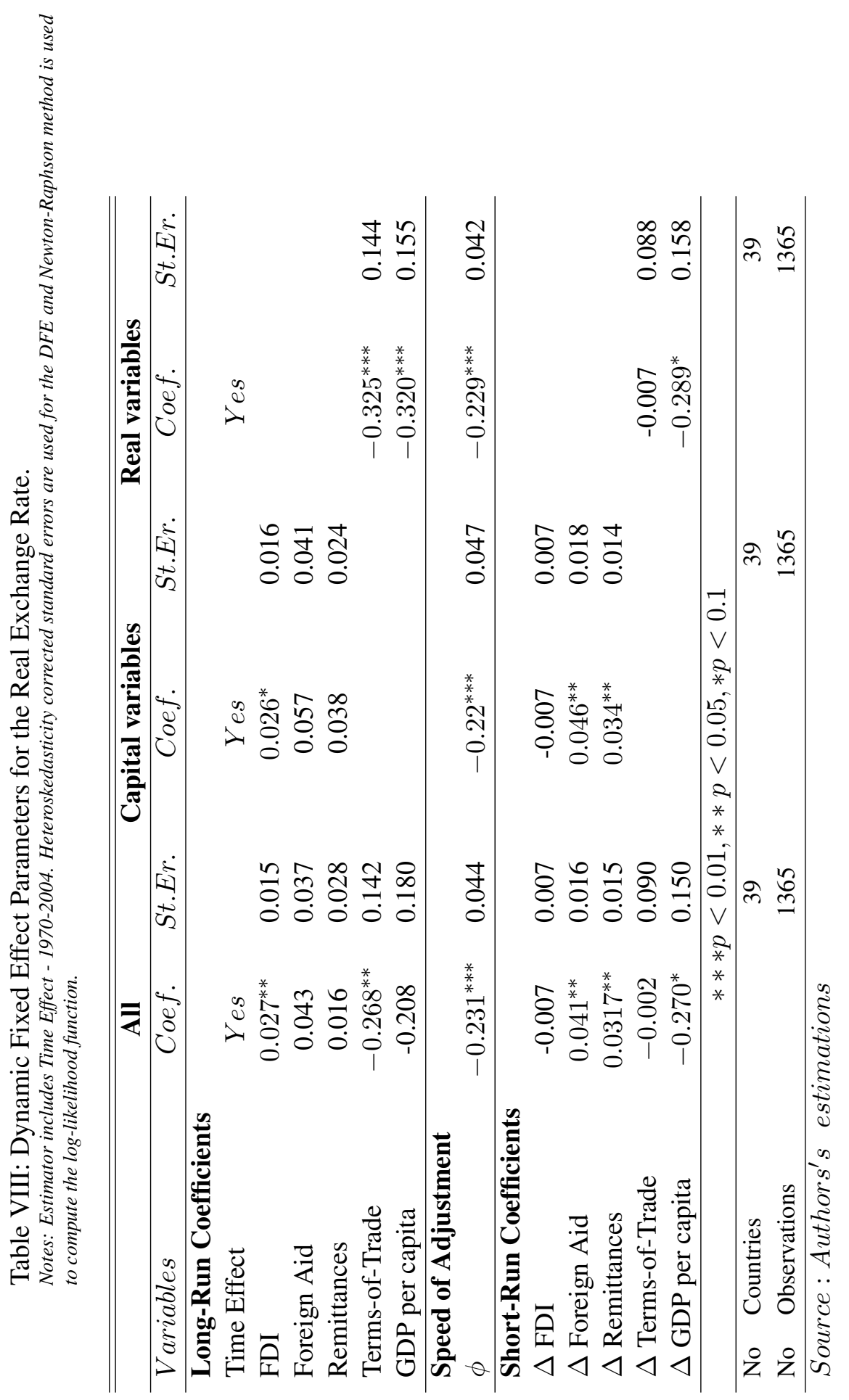




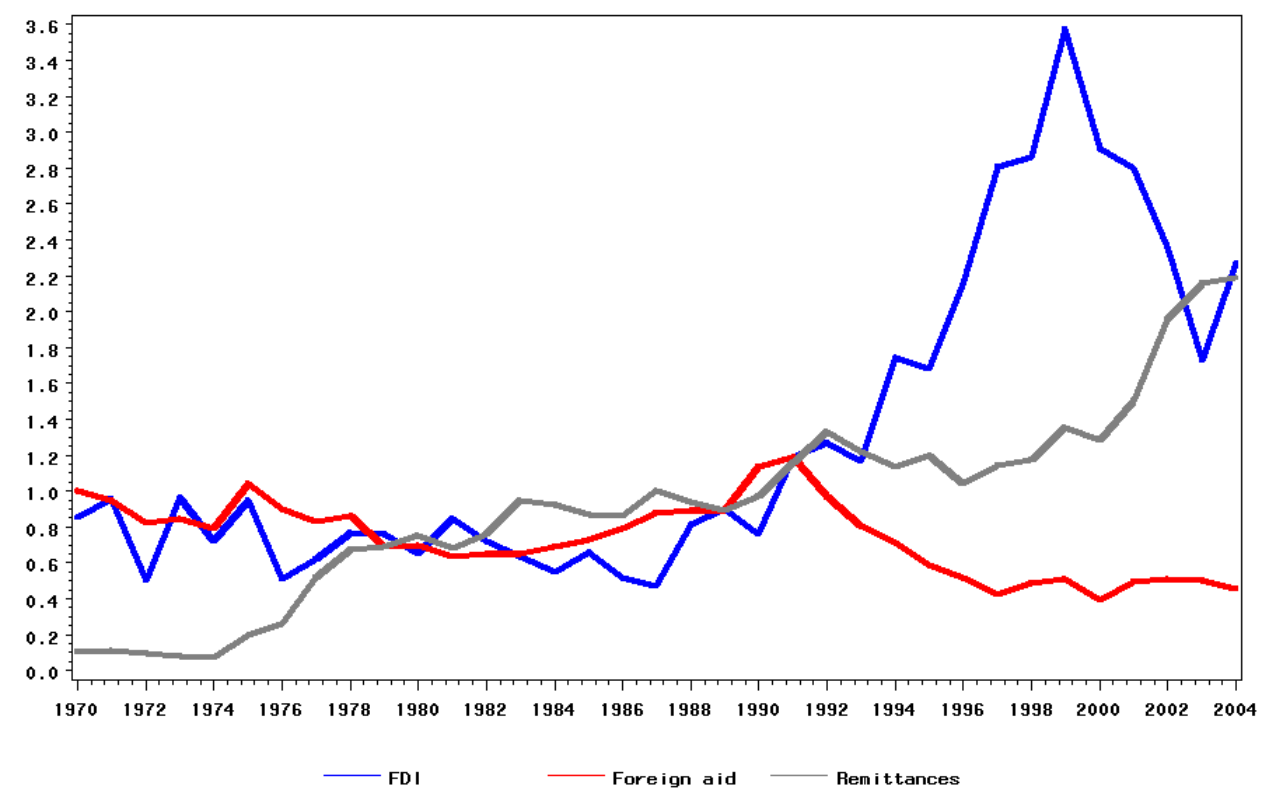

Figure 1: Capital Inflows in LDCs over GDP - 1970-2004

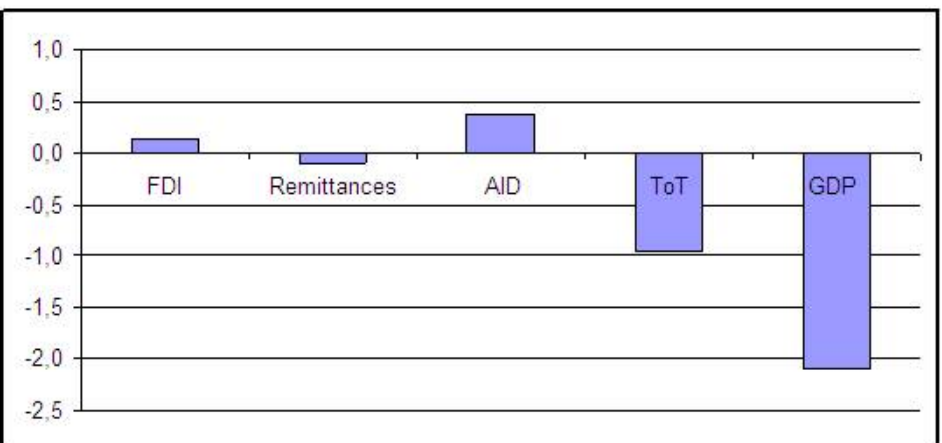

Figure 2: Implied Net Effect of Each Variable on RER. 


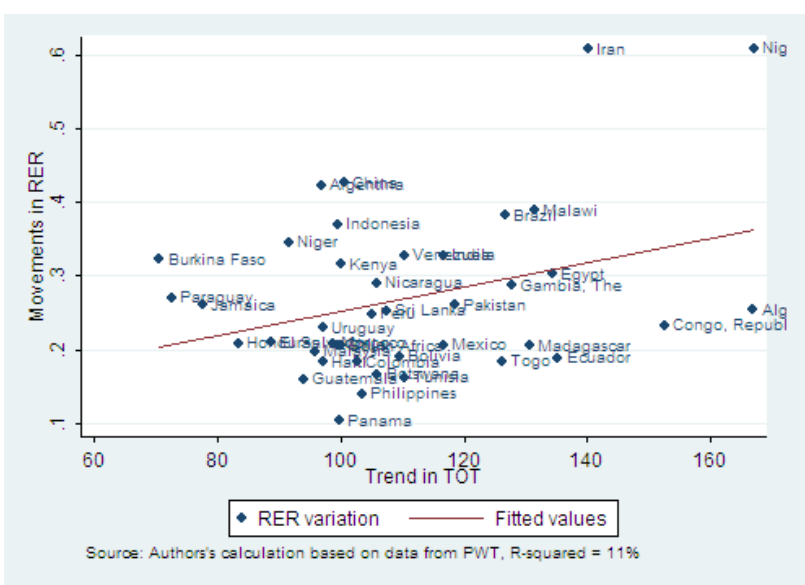

(a) RER variation vs TOT 1970-2004

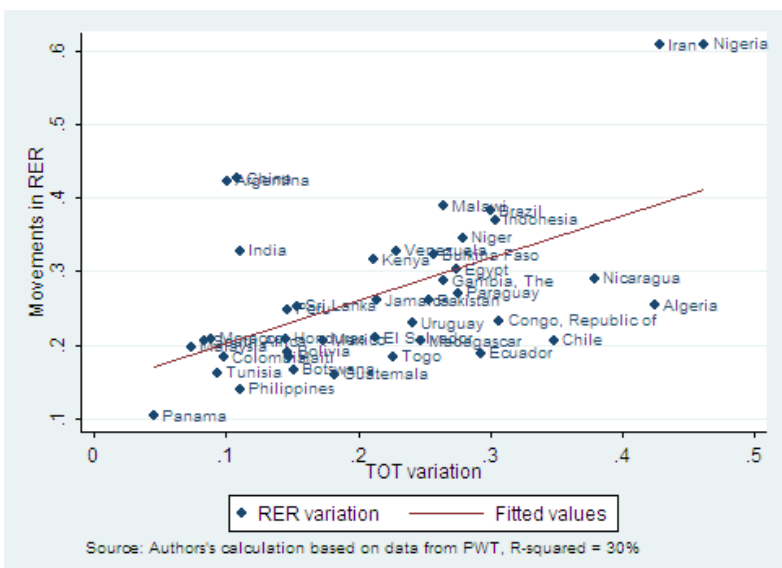

(c) RER variation vs TOT variation 1970-2004

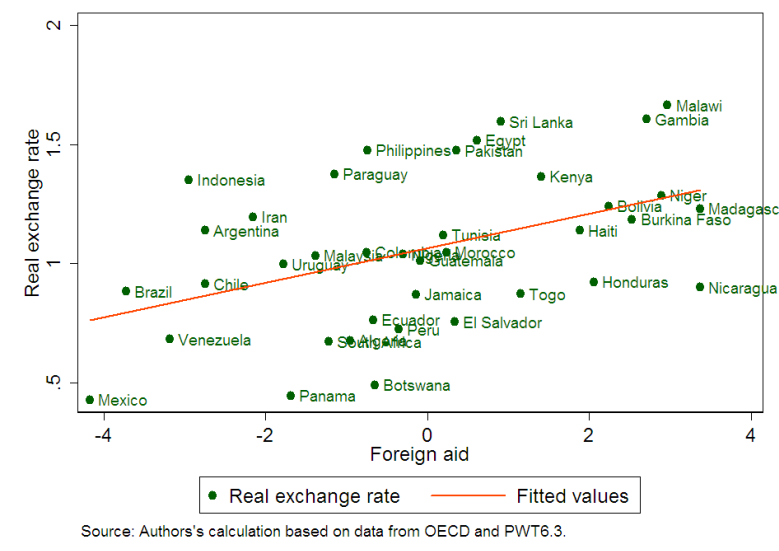

(e) RER and Foreign Aid in 2004

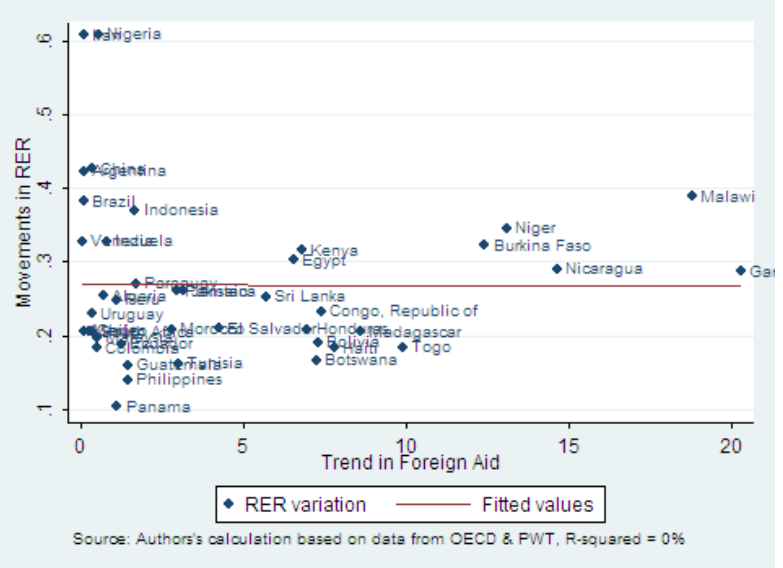

(b) RER variation vs AID 1970-2004

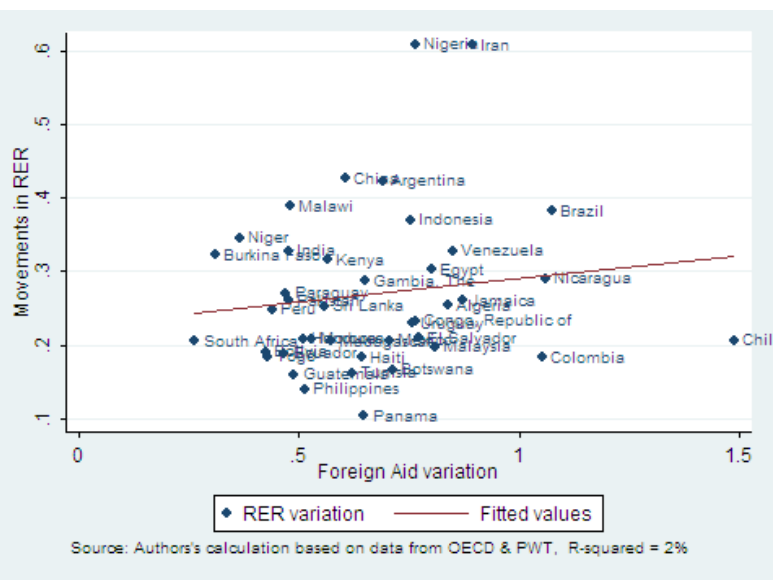

(d) RER variation vs AID variation 1970-2004

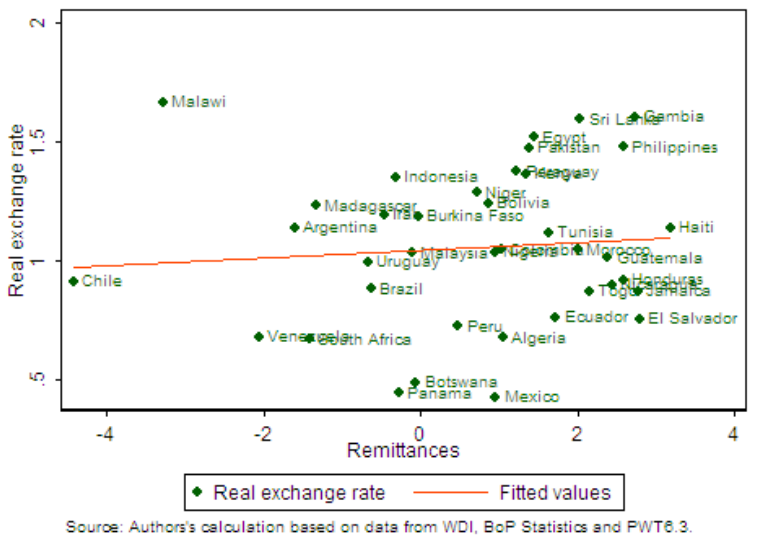

(f) RER and Remittances in 2004

Figure 3: Bivariate Scatterplots between RER and some of its Determinants. 


\section{Bibliography}

Arellano, M., and S. Bond (1991): "Some Tests of Specification for Panel Data: Monte Carlo Evidence and an Application to Employment Equations," Review of Economic Studies, 58(2), 277-97. 12, 15

Asea, P. K., and E. G. Mendoza (1994): "The Balassa-Samuelson Model: A General-Equilibrium Appraisal," Review of International Economics, 2(3), 244-67. 4

Balassa, B. (1964): “The Purchasing-Power Parity Doctrine: A Reappraisal," Journal of Political Economy, 72, 584. 1, 3

Barder, O. (2006): “A Policymakers' Guide to Dutch Disease,” Center for Global Development, Working Paper 91.2

Burnside, C., and D. Dollar (2000): “Aid, Policies, and Growth,” American Economic Review, 90(4), 847-868. 2

Corden, W. M., and J. P. Neary (1982): "Booming Sector and De-Industrialisation in a Small Open Economy," Economic Journal, 92(368), 825-48. 9

Doucouliagos, H., and M. Paldam (2009): "The Aid Effectiveness Literature: The Sad Results Of 40 Years Of Research,” Journal of Economic Surveys, 23(3), 433-461. 2

Galstyan, V., and P. R. Lane (2009): "The Composition of Government Spending and the Real Exchange Rate," Journal of Money, Credit and Banking, 41(6), 1233-1249. 9

Granger, C. W. J., and P. Newbold (1974): "Spurious regressions in econometrics," Journal of Econometrics, 2(2), 111-120. 13

Im, K. S., M. H. Pesaran, and Y. Shin (2003): “Testing for unit roots in heterogeneous panels," Journal of Econometrics, 115(1), 53-74. 19

Imbs, J., H. Mumtaz, M. Ravn, and H. Rey (2005): "PPP Strikes Back: Aggregation and the Real Exchange Rate," The Quarterly Journal of Economics, 120(1), 1-43. 12

Johansen, S. (1996): Likelihood-Based Inference in Cointegrated Vector Autoregressive Models. Oxford University Press. 14

Keynes, J. M. (1929): “The Reparation Problem: A Discussion,” The Economic Journal, 39(154), pp. 172-182. 1, 3, 4, 14

Lane, P. R., and G. M. Milesi-Ferretti (2004): “The Transfer Problem Revisited: Net Foreign Assets and Real Exchange Rates," The Review of Economics and Statistics, 86(4), 841-857. 2

Lartey, E. K. K. (2007): "Capital inflows and the real exchange rate: An empirical study of sub-Saharan Africa," Journal of International Trade \& Economic Development, 16(3), 337-357. 15

Levin, A., C.-F. Lin, and C.-S. James Chu (2002): "Unit root tests in panel data: asymptotic and finitesample properties," Journal of Econometrics, 108(1), 1-24. 18 
Loayza, N. V., and R. Rancière (2006): "Financial Development, Financial Fragility, and Growth," Journal of Money, Credit and Banking, 38(4), 1051-1076. 10

Nelson, C. R., and C. R. Plosser (1982): "Trends and random walks in macroeconmic time series: Some evidence and implications," Journal of Monetary Economics, 10(2), 139 - 162. 12

Nwachukwu, J. (2008): "Foreign Capital Inflows, Economic Policies and the Real Exchange Rate in Sub Saharan Africa: Is there an Interaction Effect? A Policymakers' Guide to Dutch Disease," Brooks World Poverty Institute, Working Paper 25. 15

Ouattara, B., and E. Strobl (2008): "Foreign Aid Inflows And The Real Exchange Rate In The Cfa Franc Zone," Economie Internationale, (4Q), 37-52. 15

Pesaran, M. H. (2007): "A simple panel unit root test in the presence of cross-section dependence," Journal of Applied Econometrics, 22(2), 265-312. 19, 20, 21, 22

Pesaran, M. H., Y. Shin, and R. P. Smith (1999): "Pooled Mean Group Estimation of Dynamic Heterogeneous Panels," Journal of the American Statistical Association, 94(446), pp. 621-634. 13, 14

Pesaran, M. H., and R. Smith (1995): "Estimating long-run relationships from dynamic heterogeneous panels," Journal of Econometrics, 68(1), 79-113. 12, 13

Rajan, R. G., and A. Subramanian (2008): "Aid and Growth: What Does the Cross-Country Evidence Really Show?," The Review of Economics and Statistics, 90(4), 643-665. 2

(2011): “Aid, Dutch disease, and manufacturing growth," Journal of Development Economics, 94(1), 106-118. 15

Rodrik, D. (2008): “The Real Exchange Rate and Economic Growth," Brookings Papers on Economic Activity, 2008, pp. 365-412. 10

Rogoff, K. (1996): “The Purchasing Power Parity Puzzle,” Journal of Economic Literature, 34(2), pp. 647-668. 10, 12

Samuelson, P. A. (1952): "The Transfer Problem and Transport Costs: The Terms of Trade When Impediments are Absent," The Economic Journal, 62(246), pp. 278-304. 4

(1964): “Theoretical Notes on Trade Problems," The Review of Economics and Statistics, 46(2), pp. 145-154. 1, 3

Soto, R., and I. Elbadawi (2007): "Theory and Empirics of Real Exchange Rates in Developing Countries," Working Papers 324, Pontificia Universidad Catolica de Chile. 15

Stahl, C. W., and F. Arnold (1986): “Overseas Workers' Remittances in Asian Development,” International Migration Review, 20(4), pp. 899-925. 11

Tokarick, S. (2008): "Welfare-Worsening Aid Flows To Small Countries: The Role of Nontraded Goods," Review of Development Economics, 12(4), 818-827. 9 
Wickens, M. (2008): Macroeconomic Theory: A Dynamic General Equilibrium Approachchap. 7, pp. 144-175. Princeton University Press, Princeton, NJ. 4

Yano, M., and J. B. Nugent (1999): "Aid, Nontraded Goods, and the Transfer Paradox in Small Countries," American Economic Review, 89(3), 431-449. 1, 3, 4, 15 